\title{
Effectiveness of management for yips in sports: A systematic review.
}

\author{
Koya Mine ${ }^{1,2 *}$, Kenta Ono ${ }^{3}$, Nobuhito Tanpo ${ }^{4}$ \\ ${ }^{1}$ Department of Physical Therapy, School of Health Sciences, Tokyo University of Technology, Tokyo, Japan \\ ${ }^{2}$ International Centre for Allied Health Evidence, University of South Australia, Adelaide, Australia \\ ${ }^{3}$ Department of Rehabilitation, Kuwano Kyoritsu Hospital, Fukushima, Japan \\ ${ }^{4}$ Department of Rehabilitation, Takeda General Hospital, Fukushima, Japan
}

\begin{abstract}
Yips is generally described as a spectrum of psychoneuromuscular movement disorders during specific sporting tasks. To date, no single systematic review has been produced with regard to effective management for this difficult condition. The purpose of this systematic review was to collect and examine primary research examining the effectiveness of management for yips. Seven electronic databases were searched. Primary studies investigating any interventions for yips symptoms were included. The McMaster Critical Review Form was used to evaluate the methodological quality of included studies. Twelve papers with low levels of evidence were included. Overall study quality was low. We found limited evidence to support the positive effects of motor imagery for golfers with type I yips. There was virtually no formal evidence to support or negate medications, botulinum toxin injections, pre-performance routines and other interventions for yips. Therefore, no definitive conclusion can be made with regard to the effectiveness of any management for yips. Future studies with better methodological rigor are required to inform athletes, coaches and clinician.
\end{abstract}

Keywords: Yips, Task-specific dystonia, Choking, Sports, Systematic review.

\section{Introduction}

Yips is a difficult and puzzling condition for athletes, coaches and health-related professionals [1,2]. Although no clear-cut definition has been established, yips has been generally described as a psychoneuromuscular movement disorder during specific tasks exaggerated by heightened pressure and anxiety, resulting in compromised performance in sports [1,3]. This condition has been often reported in specific sports which require well-learned precise skills, such as golf, baseball, cricket, ten pin bowling, archery, shooting, snookers and darts [1,3-7]. Particularly, most of the literature has investigated yips in golf. The prevalence among golfers is speculated to be high, ranging from $28 \%$ to $54 \%[8,9]$. The figures are varied due to the absence of the universal diagnostic criteria [10]. Athletes' performance is negatively affected by yips. This condition can enforce tremendous amount of mental stress to athletes, forcing them to terminate their careers in detrimental cases [9].

Pathophysiology of yips is still unclear. Hence, yips are often clinical diagnoses based on subjective examinations [11]. It was suggested that yips might be a continuum of task-specific focal dystonia (type I yips) and choking (type II yips) [12]. Task-specific focal dystonia is characterized by involuntary movements in highly overlearned movement patterns in specific tasks [13]. It is often described as "jerk", "twitch", "tremor", "spasm", "cramp" or "freezing" of muscles [4]. This condition has been also reported in musicians and writers as well as athletes [14,15]. One paper demonstrated that the somatosensory finger representations in the cortex were distorted and the receptive fields of fingers overlapped in musicians with focal dystonia [16]. In writer's cramp, altered cortical representation and deficient basal ganglia activity have been identified [17]. These findings suggest that dysfunctional sensorimotor processing in brains might be associated with type I yips [13]. On the other hand, choking is typically described as a significant failure of motor performance due to excessive mental pressure [18]. This presentation has been proposed to be associated with self-consciousness and anxiety, and reinvestment, which means the tendency to consciously control well-learned skills under pressure [19,20]. Since psychological pressures are thought to exacerbate type I yips (focal dystonia) too, it seems to be hard to distinguish those two ends of the spectrum clearly [9].

In terms of management, various recommendations have been proposed for athletes with yips, mostly with anecdotal evidence. Common interventions include motor imagery [21], pre-performance routines [22], outward intentional shift with music [23], sensory tricks such as changing grips or putters in golf [24], muscle relaxants [11], botulinum toxin [25], the use of $\beta$-blockers or alcohol [2] and acupuncture [26]. These diverse ranges of treatment options might imply the absence of definitive interventions with robust research evidence. Although there is some narrative reviews on yips, to date, no systematic review specifically regarding the effectiveness of management for athletes with yips has been published $[1,2,11]$. Therefore, it is thought to be helpful for us to systematically review existing primary studies and present the best current research evidence to inform athletes, coaches and clinicians. 
Citation: Mine K, Ono K, Tanpo N. Effectiveness of management for yips in sports: A systematic review. J Phys Ther Sports Med 2018;2(1): $17-25$.

The purpose of this paper was to collect, evaluate and synthesize primary research with regard to the effectiveness of management for yips in sports.

\section{Methods}

\section{Review format and protocol}

This systematic review was written with the guidance of the Preferred Reporting Items for Systematic reviews and MetaAnalyses (PRISMA) statement [27]. This review was had been registered in an international database for systematic reviews prospectively (registration number; CRD42016053001). Due to the nature of the research design, this study was exempt from a review by an ethics committee.

\section{Eligibility criteria}

A PICOS (participants, intervention, comparator intervention, outcome measures and study design) format for the clinical question and search key words are illustrated in Table 1 [28]. Only peer-reviewed primary research investigating the effects of management for yips symptoms were included in this review. Papers investigating focal dystonia among other population, such as musicians or writers were excluded. Due to the apparent paucity of primary studies in this area, studies any research designs or interventions were considered for eligibility. Articles written in English or Japanese were considered for eligibility. Abstracts without full texts, brief reports, editorials and academic dissertations were excluded.

Table 1. PICOS format and search key words.

\begin{tabular}{lll}
\hline & Definition & Search Key Words \\
\hline Population & Athletes with yips & $\begin{array}{l}\text { (yips OR dystonia OR choking) AND } \\
\text { (sport OR athlete OR player OR golf } \\
\text { OR baseball) }\end{array}$ \\
\hline Intervention & Any interventions & not set \\
\hline Comparison & $\begin{array}{l}\text { Any comparator } \\
\text { interventions }\end{array}$ & not set \\
\hline Outcome & Symptoms of yips & not set \\
\hline Study Design & $\begin{array}{l}\text { Any primary } \\
\text { studies }\end{array}$ & not set \\
\hline
\end{tabular}

\section{Data sources and search strategy}

A systematic search of the literature from inceptions to 18 April 2018 was conducted. Seven databases, including CINAHL, CiNii, Cochrane Library, Embase, Ichushi, MEDLINE and SPORTDiscus were utilized. In the search, studies were limited to research with human participants and English or Japanese-language research, depending on each database's setting. After an initial search, duplicates were excluded. Titles and abstracts were screened to remove irrelevant articles. Finally, full texts of potentially relevant papers were reviewed for eligibility. Relevant studies in reference lists of included studies were also searched. The systematic search was processed through EndNote X7 software (Clarivate Analytics, USA).

\section{Quality assessment for included studies}

Due to the apparent absence of randomized controlled trials (RCTs), identified in a preliminary search, the assessment of the methodological quality was performed using the McMaster Critical Review Form for Quantitative Studies [29]. Included papers were assessed by one reviewer (KY) at first. The results were subsequently verified by other two independent reviewers (NT, KO). When discrepancies occurred among three assessors, a consensus was obtained through discussions. Percentage scores were calculated to make a consistent comparison across studies with different research designs. Studies with a score of $50 \%$ or less were considered to be lowquality, whilst between $51 \%$ and $75 \%$ being moderate-quality and $>75 \%$ as high-quality to enable a convenient nominal judgment.

\section{Data extraction and analysis}

Data regarding study design, sample characteristics (sample size, age, gender and athletic competency levels), types of interventions, outcome measures, results (pre- and postintervention data, statistical significance and effect sizes) and conclusions were collected. Hedges' g and 95\% confidence intervals (CI) were calculated to estimate effect sizes, based on available data to evaluate clinical significance of the results [30]. Effect sizes were evaluated as trivial (0-0.19), small (0.20-0.49), medium (0.50-0.79) and large (0.80 and greater) [31]. Meta-analysis and subgroup analysis were not expected to be undertaken due to the apparent absence of homogeneity among studies and sufficient data set.

\section{Results}

\section{Study selection}

The process of systematic search is illustrated in Figure 1. The initial systematic search yielded 394 potentially relevant papers. After the removal of 80 duplicate studies, 297 articles were excluded based on their titles and abstracts. 17 full texts of remaining papers were assessed with regard to eligibility. Of the 17 studies, five studies were excluded due the absence of yips symptoms in recruited athletes [32-36]. One Japaneselanguage study was excluded because the type of yips was not clear in the study [37]. Although the corresponding author was contacted, the required information was not available. One relevant article was identified in the reference lists of included studies [38]. As a result, 12 studies were included for the review. All included studies had been published in English.

\section{Study Characteristics}

A summary of the 12 included studies is described in Table 2. The numbers of athletes analysed in the included studies were consistently low, ranging from one to four. In total, 27 athletes had been investigated in the included studies. 


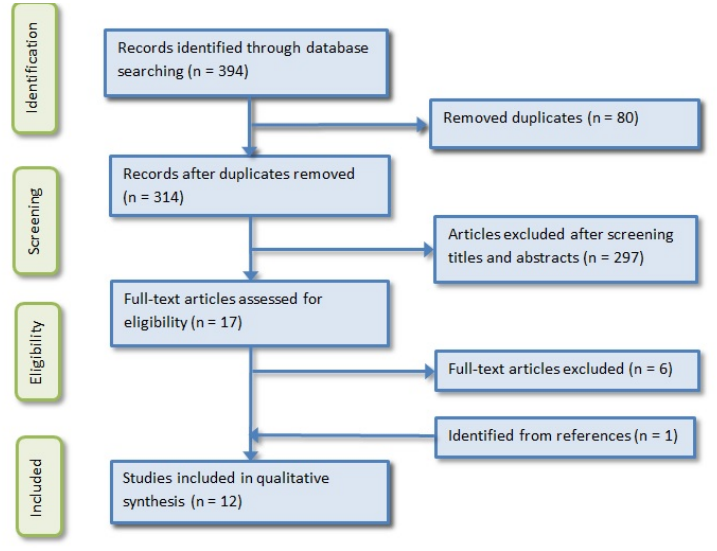

Figure 1. Flowchart of the study selection.

Nine studies examined on athletes suffering from type I yips, where focal dystonia was the feature of their symptoms; whilst three studies included athletes with type II yips, where choking was the dominant presentation. Seven out of 12 studies recruited golfers with yips. Other sports performed by participants were long-distance running [39,40], basketball [23], tenpin bowling [22] and rowing [41]. Ages of participants varied greatly, ranging from 19 to 65 years old.

Common interventions in the included papers were motor imagery $[21,38,42,43]$, pre-performance routines [22,43,44], and medications and botulinum toxin injection $[39,40]$. Commonly utilized outcome measures were the number or frequency of yips $[21,38,42,44]$, performance in specific sports tasks $[22,23,43,45]$ and various psychological questionnaire [22,23,37,44,45]. A subjective assessment regarding general improvement was performed in unclear manners in four studies $[26,39,40,43]$. Study designs consistently had low levels of evidence; single case design in six articles, case series in three articles and case report in three articles.

Table 2. Summary of included studies.

\begin{tabular}{|c|c|c|c|c|}
\hline Study & Participants & Interventions & Outcome measures & Results \\
\hline $\begin{array}{l}\text { Milne and Morrison } \\
\text { [44] }\end{array}$ & $\begin{array}{l}\mathrm{N}=1 \\
52 \text {-year-old male golfer } \\
\text { with type I yips } \\
\text { 22-year experience } \\
\text { Unclear duration or } \\
\text { laterality of symptoms } \\
\text { Involuntary jerk during a } \\
\text { chip shot and temporary } \\
\text { freezing just after the shot } \\
\text { (type } 1 \text { yips) }\end{array}$ & $\begin{array}{l}\text { - Interview to formulate the } \\
\text { mechanism of symptoms } \\
\text { - Instillation of positive instructional } \\
\text { self-talk during shots } \\
\text { - } \quad \text { Pre-performance routine } \\
\text { Breathing exercises } \\
\text { Although an exact intervention period } \\
\text { was not given, it is assumed to be } 1-2 \\
\text { months }\end{array}$ & 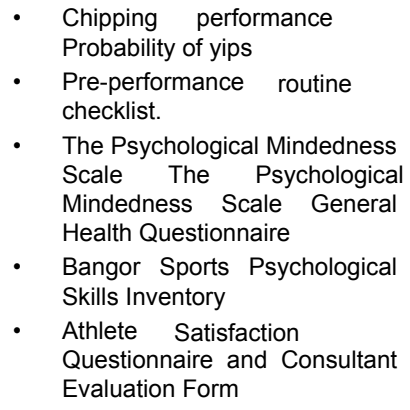 & $\begin{array}{l}\text { - Adherence to pre-performance } \\
\text { routine improved from } 40 \% \text { to } \\
100 \% \text {. } \\
\text { - The golfer was highly satisfied } \\
\text { with the intervention, equating to } \\
88 \text { per cent approval. } \\
\text { Chipping performance improved } \\
\text { after the three-month } \\
\text { interventions. } \\
\text { - Frequency of yips significantly } \\
\text { reduced }(p<0.05) \text {. }\end{array}$ \\
\hline Rotheram et al. [45] & $\begin{array}{l}\mathrm{N}=1 \\
49-\text {-year-old male golfer } \\
\text { with type I yips } \\
\text { Six-year history of yips }\end{array}$ & $\begin{array}{l}\text { Four sessions of two-hour emotional } \\
\text { freedom technique, lasting for three } \\
\text { weeks in total }\end{array}$ & $\begin{array}{ll}\text { - } & \text { Putting success rate } \\
\text { - } & \text { Kinematic motion analysis } \\
\text { - } & \text { Visual inspection } \\
& \text { Social validation questionnaire }\end{array}$ & $\begin{array}{l}\text { - Putting success rate consistently } \\
\text { improved after treatments and at } \\
\text { six-month follow-up } \\
\text { - By the end of the intervention, } \\
\text { visual occurrence of yips subsided } \\
\text { - Participants 'felt something shift' } \\
\text { or 'felt free' after the intervention. }\end{array}$ \\
\hline Hill et al. [43] & $\begin{array}{l}\mathrm{N}=2 \\
\text { 22-year-old-male } \\
\text { professional golfer with } \\
\text { type II yips }\end{array}$ & $\begin{array}{l}\text { The following interventions were } \\
\text { performed for } 10 \text { months. } \\
\text { - } \quad \text { Reflective diary } \\
\text { - } \quad \text { Pre-performance routine } \\
\text { - } \quad \text { Motor imagery }\end{array}$ & $\begin{array}{l}\text { Subjective assessment } \\
\text { regarding improvement }\end{array}$ & $\begin{array}{l}\text { - The numbers of choking reduced } \\
\text { in both participants after the } \\
\text { interventions. }\end{array}$ \\
\hline Bell et al. [38] & $\begin{array}{l}\mathrm{N}=4 \\
51 \text {-year-old (mean age) } \\
\text { male golfers with type I } \\
\text { yips More than 20-year } \\
\text { experience }\end{array}$ & $\begin{array}{l}\text { - Motor imagery } \\
3-5 \text { sessions of solution-focused motor } \\
\text { imagery were performed for each } \\
\text { golfer. Intervention periods were not } \\
\text { given. }\end{array}$ & $\begin{array}{l}\text { - Average number of yips per } \\
\text { round }\end{array}$ & $\begin{array}{l}\text { Results supported previous } \\
\text { research that found motor imagery } \\
\text { to decrease yips. }\end{array}$ \\
\hline Bell et al. [42] & $\begin{array}{l}\mathrm{N}=3 \\
51 \text {-year-old (mean age) } \\
\text { male golfers with type I } \\
\text { yips More than } 20 \text { years- } \\
\text { year experience }\end{array}$ & $\begin{array}{l}\text { Motor imagery } \\
\text { Five sessions of } 20 \text {-minute solution- } \\
\text { focused motor imagery were performed } \\
\text { for each golfer. Interventions lasted for } \\
\text { two weeks in total. }\end{array}$ & $\begin{array}{l}\text { - Average number of yips per } \\
\text { round }\end{array}$ & $\begin{array}{l}\text { Data collected during participants' } \\
\text { regularly scheduled weekly golf } \\
\text { rounds showed an immediate and } \\
\text { sustained decrease in yips after } \\
\text { motor imagery sessions. } \\
\text { - Maintenance data collected three } \\
\text { weeks after the last sessions } \\
\text { showed that these decreases } \\
\text { were maintained. }\end{array}$ \\
\hline
\end{tabular}


Citation: $\quad$ Mine K, Ono K, Tanpo N. Effectiveness of management for yips in sports: A systematic review. J Phys Ther Sports Med 2018;2(1): 17-25.

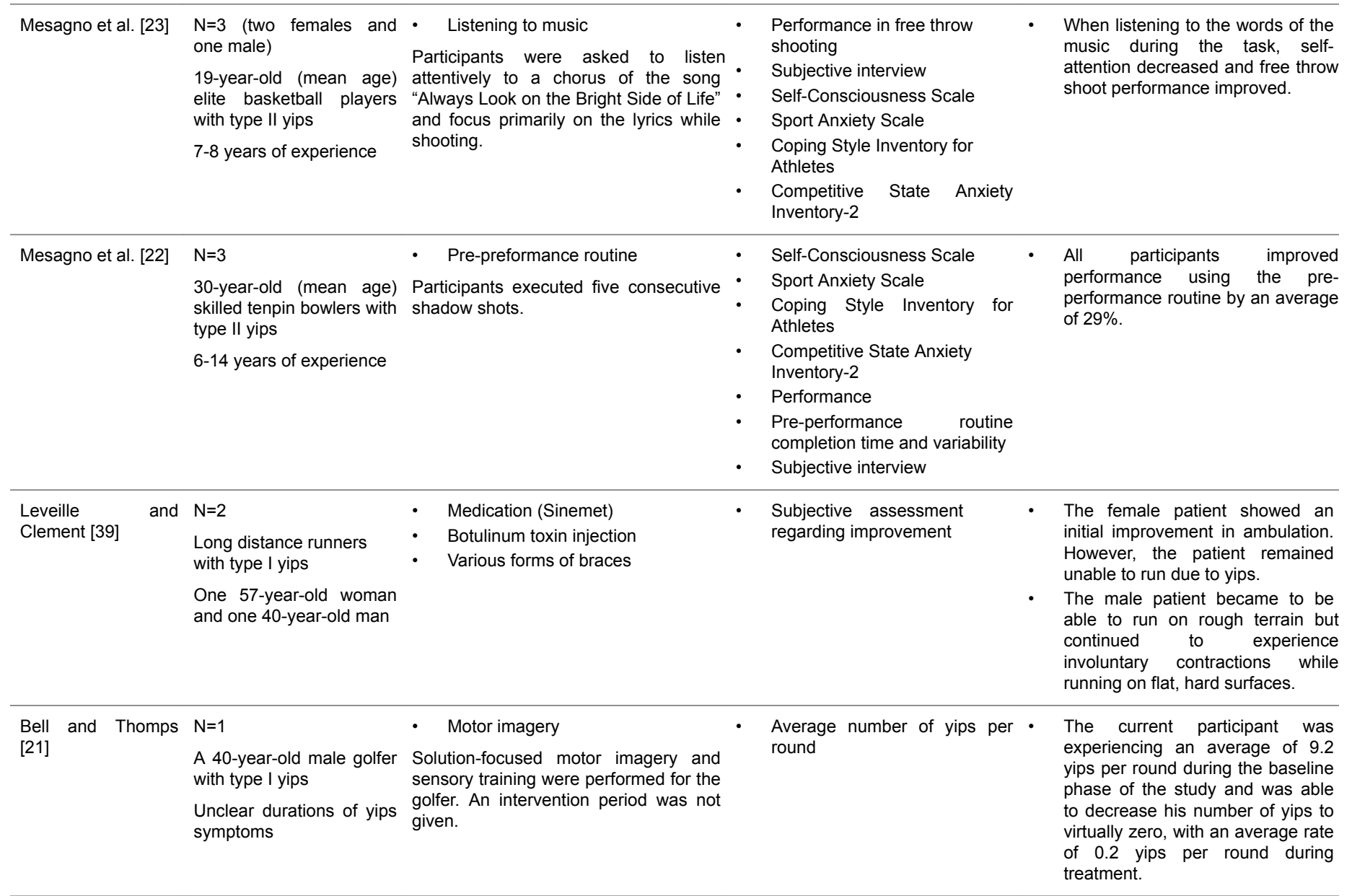

\begin{tabular}{|c|c|c|c|c|}
\hline Kobori [41] & $\begin{array}{l}\mathrm{N}=1 \\
\text { A } 21 \text {-year-old male rower } \\
\text { with type I yips } \\
\text { Two-year experience of } \\
\text { rowing One-year history } \\
\text { of yips }\end{array}$ & $\begin{array}{l}\text { Seven sessions were performed during } \\
\text { seven-month period. } \\
\text { - } \quad \text { Reassurance } \\
\text { - } \quad \text { Development of the idiosyncratic } \\
\text { model of the symptom } \\
\text { - } \quad \text { Education to other team members } \\
\text { - } \quad \text { Relaxation training } \\
\text { - } \quad \text { Behavioural technique } \\
\text { - } \quad \text { Cognitive reconstructuring }\end{array}$ & $\begin{array}{l}\text { - Subjective sensation of the yips } \\
\text { symptom (0 to 100) }\end{array}$ & $\begin{array}{l}\text { The ratings regarding the symptom } \\
\text { reduced from } 90 \text { at the baseline to } 15 \\
\text { at eight-month follow-up. }\end{array}$ \\
\hline \multirow[t]{2}{*}{$\begin{array}{l}\text { Wu and Jankovic } \\
{[40]}\end{array}$} & $\begin{array}{l}\mathrm{N}=5 \text { (three females and } \\
\text { two males) } \\
45-\text { year-old (mean) long- } \\
\text { distance runners with } \\
\text { type I yips }\end{array}$ & $\begin{array}{ll}\text { - } & \text { Medication (Carbamazepine, } \\
\text { Levodopa or Trihexyphenidyl) } \\
\text { - } \quad \text { Botulinum toxin injection } \\
\text { - Hypnotherapy }\end{array}$ & $\begin{array}{l}\text { - Subjective assessment } \\
\text { regarding improvement }\end{array}$ & \multirow[t]{2}{*}{$\begin{array}{l}\text { Each intervention was effective, } \\
\text { although there was no analysis for any } \\
\text { outcome measures. }\end{array}$} \\
\hline & $\begin{array}{l}\text { Mean duration of } \\
\text { symptoms: } 7.2 \pm 4.4\end{array}$ & & & \\
\hline Rosted [26] & $\begin{array}{l}\mathrm{N}=1 \\
\text { A } 65 \text {-year-old male golfer } \\
\text { with type I yips } \\
\text { More than } 30 \text {-year } \\
\text { experience of golf }\end{array}$ & $\begin{array}{l}\text { - Acupuncture (GV20, EX-HN-1 and } \\
\text { TE5 } \\
\text { Intervention period was unclear. }\end{array}$ & $\begin{array}{l}\text { - Subjective assessment } \\
\text { regarding improvement }\end{array}$ & $\begin{array}{l}\text { The patient claimed that his symptoms } \\
\text { had disappeared after the first } \\
\text { intervention and its effect was } \\
\text { maintained at A follow up by phone call } \\
\text { six, twelve and } 24 \text { months after } \\
\text { termination of the intervention. }\end{array}$ \\
\hline
\end{tabular}

\section{Methodological Quality}

The results of critical appraisal using MCRF are presented in Table 3. Overall, the study quality was low standard with a mean score of $38 \%$. The study qualities ranged from moderate $(62 \%)$ to low $(23 \%)$. The majority of the included studies were categorized as low-quality $(n=10)$, whilst only two studies were regarded to have moderate quality $[41,44]$.
Common methodological flaws were; not addressing the reliability $(100 \%)$ or validity of outcome measures $(100 \%)$, no detailed explanation regarding interventions to allow replications (100\%), inappropriate analysis methods (100\%), no justification for sample size $(92 \%)$, no clarification to avoid contamination $(92 \%)$ and no analysis in terms of statistical significance $(92 \%)$. 


\section{Data Extraction and Analysis}

Due to the heterogeneity of the included studies and insufficient data set, meta-analysis was not possible. Thus, descriptive analysis and synthesis were attempted. An additional analysis was performed by calculating betweengroup effect sizes and $95 \%$ CI in three papers, where quantitative data was available to enable effect size calculation $[23,38,42]$. The results of further analysis using effect sizes are shown in Table 4.

\section{Effects of Motor Imagery for Type I Yips}

The same author group examined the effects of motor imagery, which they specifically called solution-focused guided imagery, on golfers with type I yips in three comparative study with single-case design [21,38,42]. Sample sizes were four, three and one respectively. During motor imagery, facilitators guided subjects to create vivid images without yips symptoms. These low-quality studies consistently reported improvements in their symptoms and performance with moderate to large effect sizes. Our further analysis to calculate confirmed that effect sizes were consistently large and statistically significant (refer to Table 4).

Considering the low levels of evidence, low methodological qualities and large effect sizes in the studies, there seems to be limited evidence to support the positive effects of motor imagery for golfers with type I yips.

\section{Effects of Medication and Botulinum Toxin Injection for Type I Yips}

Two low-quality case series with a total sample size of seven, investigated the effects of various medications and botulinum toxin injection for long distance runners with type I yips $[39,40]$. These interventions were combined with hypnotherapy in one case [40]. Prescribed medicines were Sinemet, Carbamazepine, Levodopa Trihexyphenidyl or Gabapentin, depending on a case. Both studies did not use formal outcome measures, but casually assessed athletes' subjective improvements. Patients' outcomes were broadly favourable, except for one runner who remained unable to run due to yips $[39,40]$.

Due to the low levels of evidence, low methodological qualities and the lack of statistical analysis in the studies, there is virtually no formal research evidence which suggests that medications and botulinum toxin injection are effective for athletes with any types of yips.

\section{Effects of Pre-Performance Routines}

The effects of pre-performance routines were explored in three articles, all of which did not examine statistical significance of the results $[22,43,44]$.
One low-quality study with a single case design found improvements in performance of three skilled tenpin bowlers with type II yips [22]. One low-quality case series combined a pre-performance routine and motor imagery as a 10-month intervention, and reported subjective improvements in type II yips symptoms of two professional golfers [43]. Lastly, one moderate-quality article used pre-performance routine as a part of an integrated cognitive behavioral approach, which also included an interview, instillation of positive self-talk during shots and breathing exercises [44]. The authors identified statistically significant improvements in the frequency of yips and chipping performance. The author collected data 20 times in each stage of the condition from the same golfer. Since this analysis method relies on only one subject, the findings should be interpreted critically.

Considering the low levels of evidence and the lack of statistical analysis or the dubious use of statistical analysis in the studies, there is virtually no formal research evidence to suggest that pre-performance routines can improve any types of yips.

\section{Effects of Other Interventions}

One moderate-quality case report found a subjective improvement in type I yips symptoms of a young male rower after seven-month cognitive behavioral interventions, including reassurance, education to other team members, relaxation training and cognitive reconstructuring [41]. Acupuncture was examined by one low-quality case report, where the authors claimed that they observed complete disappearance of type I yips symptoms of a male golfer, immediately after the first treatment [26]. In one low-quality case report, type I yips symptoms of a male golfer subsided after three-week emotional freedom technique sessions [45]. This specific technique involved a stimulation of twelve traditional acupuncture points on the body by tapping whilst participants are tuned into the psychologically significant life events associated with their mental trauma and make self-acceptance statements. Lastly, effects of music on free-throw performance of five basketball players with type II yips was investigated by one low-quality single-case study. There was a tendency where self-awareness decreased and performance increased under pressure when music was present. 'Always Look on the Bright Side of Life' from 'Monty Python's Life of Brian' was used in this study [46]. The authors suggested that shifting attentions from their own skills to words of the song might have prevented explicit motor program taking over their performance. In our further analysis, the effect size of the intervention was found to be large and statistically significant (see Table 4).

In summary, there is very limited evidence regarding the effects of music on type II yips of basketball players. There is virtually no formal research evidence to support the effectiveness of the cognitive behavioral intervention, 
Citation: $\quad$ Mine K, Ono K, Tanpo N. Effectiveness of management for yips in sports: A systematic review. J Phys Ther Sports Med 2018;2(1): $17-25$.

acupuncture or emotional freedom technique for athletes with any types of yips.

Table 3. Methodological quality of the included studies.

\begin{tabular}{|c|c|c|c|c|c|c|c|c|c|c|c|c|c|c|c|c|}
\hline Study & 1 & 2 & 3 & 4 & 5 & 6 & 7 & 8 & 9 & 10 & 11 & 12 & 13 & 14 & 15 & $\begin{array}{l}\text { Total Score } \\
(\%)\end{array}$ \\
\hline Milne and Morrison [44] & $\mathrm{Y}$ & $\mathrm{Y}$ & SC & $\mathrm{Y}$ & $\mathrm{Y}$ & $\mathrm{n}$ & $\mathrm{n}$ & $\mathrm{N}$ & $\mathrm{n}$ & $\mathrm{n}$ & $\mathrm{Y}$ & $\mathrm{N}$ & $\mathrm{Y}$ & $\mathrm{Y}$ & $\mathrm{Y}$ & $57 \%$ \\
\hline Rotheram et al. [45] & $\mathrm{Y}$ & $\mathrm{Y}$ & $\mathrm{CR}$ & $\mathrm{N}$ & $\mathrm{N}$ & $\mathrm{n}$ & $\mathrm{n}$ & $\mathrm{N}$ & - & $\mathrm{n}$ & $\mathrm{N}$ & $\mathrm{N}$ & $\mathrm{Y}$ & $\mathrm{Y}$ & $\mathrm{N}$ & $31 \%$ \\
\hline Hill et al. [43] & $\mathrm{Y}$ & $\mathrm{Y}$ & CS & $\mathrm{N}$ & $\mathrm{N}$ & $\mathrm{n}$ & $\mathrm{n}$ & $\mathrm{Y}$ & - & $\mathrm{n}$ & $\mathrm{N}$ & $\mathrm{N}$ & $\mathrm{Y}$ & $\mathrm{Y}$ & $\mathrm{N}$ & $38 \%$ \\
\hline Bell et al. [38] & $\mathrm{Y}$ & $\mathrm{Y}$ & SC & $\mathrm{N}$ & $\mathrm{N}$ & $\mathrm{n}$ & $\mathrm{n}$ & $\mathrm{N}$ & $\mathrm{n}$ & $\mathrm{n}$ & $\mathrm{N}$ & $\mathrm{N}$ & $\mathrm{Y}$ & $\mathrm{Y}$ & $\mathrm{Y}$ & $36 \%$ \\
\hline Bell et al. [42] & $\mathrm{N}$ & $\mathrm{Y}$ & SC & $\mathrm{N}$ & $\mathrm{N}$ & $\mathrm{n}$ & $\mathrm{n}$ & $\mathrm{Y}$ & $\mathrm{n}$ & $\mathrm{n}$ & $\mathrm{N}$ & $\mathrm{N}$ & $\mathrm{Y}$ & $\mathrm{Y}$ & $\mathrm{Y}$ & $36 \%$ \\
\hline Mesagno et al. [23] & $\mathrm{Y}$ & $\mathrm{Y}$ & SC & $\mathrm{N}$ & $\mathrm{N}$ & $\mathrm{n}$ & $\mathrm{n}$ & $\mathrm{N}$ & $\mathrm{n}$ & $\mathrm{n}$ & $\mathrm{N}$ & $\mathrm{N}$ & $\mathrm{Y}$ & $\mathrm{Y}$ & $\mathrm{Y}$ & $36 \%$ \\
\hline Mesagno et al. [22] & $\mathrm{Y}$ & $\mathrm{Y}$ & SC & $\mathrm{N}$ & $\mathrm{N}$ & $\mathrm{n}$ & $\mathrm{n}$ & $\mathrm{N}$ & $\mathrm{n}$ & $\mathrm{n}$ & $\mathrm{N}$ & $\mathrm{N}$ & $\mathrm{Y}$ & $\mathrm{Y}$ & $\mathrm{Y}$ & $36 \%$ \\
\hline Leveille and Clement [39] & $\mathrm{N}$ & $\mathrm{Y}$ & CS & $\mathrm{N}$ & $\mathrm{N}$ & $\mathrm{n}$ & $\mathrm{n}$ & $\mathrm{N}$ & - & $\mathrm{n}$ & $\mathrm{N}$ & $\mathrm{N}$ & $\mathrm{Y}$ & $\mathrm{Y}$ & $\mathrm{Y}$ & $31 \%$ \\
\hline Bell and Thompson[21] & $\mathrm{N}$ & $\mathrm{Y}$ & SC & $\mathrm{N}$ & $\mathrm{N}$ & $\mathrm{n}$ & $\mathrm{n}$ & $\mathrm{Y}$ & $\mathrm{n}$ & $\mathrm{n}$ & $\mathrm{N}$ & $\mathrm{N}$ & Y & $\mathrm{Y}$ & $\mathrm{Y}$ & $36 \%$ \\
\hline Kobori [41] & $\mathrm{Y}$ & $\mathrm{Y}$ & CR & $\mathrm{Y}$ & $\mathrm{N}$ & $\mathrm{n}$ & $\mathrm{n}$ & $\mathrm{Y}$ & - & $\mathrm{Y}$ & $\mathrm{N}$ & $\mathrm{N}$ & $\mathrm{Y}$ & $\mathrm{Y}$ & $\mathrm{Y}$ & $62 \%$ \\
\hline Wu and Jankovic [40] & $\mathrm{N}$ & $\mathrm{Y}$ & CS & $\mathrm{N}$ & $\mathrm{N}$ & $\mathrm{n}$ & $\mathrm{n}$ & $N$ & - & $\mathrm{n}$ & $\mathrm{N}$ & $\mathrm{N}$ & $\mathrm{Y}$ & $\mathrm{Y}$ & $\mathrm{N}$ & $23 \%$ \\
\hline Rosted [26] & $\mathrm{N}$ & $\mathrm{N}$ & CR & $\mathrm{Y}$ & $\mathrm{N}$ & $\mathrm{n}$ & $\mathrm{n}$ & $\mathrm{Y}$ & - & $\mathrm{n}$ & $\mathrm{N}$ & $\mathrm{N}$ & $\mathrm{Y}$ & $\mathrm{Y}$ & $\mathrm{Y}$ & $38 \%$ \\
\hline
\end{tabular}

MCRF: $Y=$ Yes (one point); $N=$ No (no point), $n=$ not addressed (no point), - = not applicable (excluded), Item 3 'study design' does not yield points. SC = single case design. $C S=$ case series. $C R=$ case report.

Items: 1 . study purpose clearly stated; 2 . background literature reviewed; 3 . study design; 4 . sample described in detail; 5 . sample size justified; 6 . outcome measure reliability reported; 7 . outcome measure validity reported; 8 . intervention described; 9 . contamination avoided; 10 . Co-intervention avoided; 11 . Results reported in terms of statistical significance; 12. Appropriate analysis methods; 13 . Clinical significance reported; 14 . Dropouts reported; 15. Conclusions appropriate; \%. 100 (total points) / 14 - the number of $-[\%]$

Table 4. A comparison of effect sizes.

\begin{tabular}{|c|c|c|c|c|}
\hline Study & Outcome measure (unit) & Intervention (timeframe) & Comparator Intervention & Effect size $(95 \% \mathrm{Cl})$ \\
\hline Bell et al. [38] & Frequency of yips (times per round) & Motor imagery (unclear) & No intervention & $2.72(1.78 \text { to } 3.66)^{*}$ \\
\hline Bell et al. [42] & Frequency of yips (times per round) & Motor imagery (unclear) & No intervention & $1.67(0.39 \text { to } 2.95)^{*}$ \\
\hline Mesagno et al. [23] & Free throw performance (successful throws) & Listening to music (during the task) & (Not applicable) & $2.99(2.57 \text { to } 3.40)^{*}$ \\
\hline
\end{tabular}

$\mathrm{CBI}=$ cognitive behavioural intervention, $\mathrm{PPR}=$ pre-performance routine, $95 \% \mathrm{CI}=95 \%$ confidence interval,

$*=95 \% \mathrm{Cl}$ excluding the value of zero

\section{Discussion}

The aim of this systematic review was to present the current research evidence regarding the effectiveness of management for yips in sports. To the best of authors' knowledge, this paper is the first systematic review on this specific clinical question. We found 12 papers investigating the effects of various interventions on yips in different sports. Only studies with lower levels of evidence, such as single-case design, case series and case reports were available. Overall study quality was low. Following the descriptive synthesis of the findings from the included studies, it appears that most current primary studies only contribute to anecdotal evidence. In other words, there is no conclusive evidence about the effectiveness of any treatment strategies for athletes with yips.
The effects of motor imagery were positive with large effect sizes for type 1 yips in three studies $[21,38,42]$. Considering that mental rotation performance is impaired among patients with focal dystonia, motor imagery might be a reasonable treatment option for atheltes with type 1 yips $[47,48]$. It has been reported that patients with chronic pain states also have impaired mental rotation capacity [49]. Specific motor imagery strategies, such as left/right discrimination and mirror therapy have been reported to be effective to treat patients with chronic pain as well as impaired motor imagery skills [50]. It has been speculated that motor imagery training can address cortical representations of impaired movements and pain perception [50]. Given that the mechanism of impaired motor imagery capacity can be potentially common in chronic pain conditions and type 1 yips, left/right discrimination and mirror therapy might be also applicable to type 1 yips. Interestingly, motor 
imagery was not examined for athletes with type 11 yips. This potential hesitation among researchers seemed to be reasonable as motor imagery might make athletes more self-conscious about their motor outputs and it may exacerbate type 11 yips symptoms.

\section{Source of Bias and Limitations of Studies}

Several limitations in the included studies should be considered to avoid overestimation of the findings. Since interventions were not explained clearly in some studies, it is difficult to replicate and test the same interventions. Potential inconsistencies in the delivery of the interventions might have biased the results. None of the studies reported reliability and validity of used outcome measures. This might have led to false positive results in some studies. The majority of the included studies failed to conduct a statistical analysis due to small sample sizes. The absence of statistical analysis restraints the reliability and generalisability of the findings. Although sample sizes were not justified by statistical calculation in any studies, small sample sizes seems to be understandable, considering the fact that it is relatively difficult to collect a sufficient number of homogenous athletes with the same types of yips. The absence of control groups in the majority of the included studies may have also resulted in bias.

\section{Implications for Research}

Given that it is impractical to conduct experimental studies with large sample sizes for this condition, single-case designs or crossover RCTs seem to be reasonable choices as desirable research designs. If it is possible to collect a sufficient number of athletes suffering from the same type of yips, researchers are strongly recommended to choose a crossover RCT (level II evidence), not case series (level IV evidence). Unlike observational studies, crossover RCTs can theoretically exclude various bias, leading to more reliable findings. Since motor imagery was reported to have large-size effects on type I yips among golfers, this intervention may be worth being explored in further studies. Further studies with better methodological rigour are required to test the effectiveness of other interventions, such as medications, botulinum toxin injections and pre-performance routines.

\section{Implications for Clinical Practice}

As research evidence is inconclusive, clinicians must combine the research evidence with their clinical expertise, athletes' values and circumstances to enable the best possible decision making. Clinicians can consider motor imagery for athletes with type 1 yips as a potential intervention. The use of other interventions, such as pre-performance routines, medications, botulinum toxin injection should be justified by athletes' individual presentations and sound clinical reasoning. Continuous assessments are required to defend adopted management strategies.

\section{Conclusion}

This systematic review revealed the paucity of evidence regarding the effectiveness of management for yips among athletes. A systematic search identified 12 papers with low levels of evidence. As a result of descriptive synthesis, the effectiveness of motor imagery for type I yips of golfers was inconclusive. There was virtually no formal evidence to support or negate medications, botulinum toxin injections, preperformance routines and other interventions for yips. Considering the potentially detrimental effects of this condition to athlete's performances and careers, the paucity of primary studies is deeply worrying. Future research should reflect methodological flaws exposed in this review and demonstrate stronger evidence to inform clinicians, coaches and athletes.

\section{Disclosure Statement}

There is no conflict of interests.

\section{References}

1. Clarke P, Sheffield D, Akehurst S. The yips in sport: A systematic review. Int Rev Sport Exerc Psychol 2015;8(1): 156-84.

2. Smith AM, Adler CH, Crews D, et al. The 'Yips' in golf. Sports Med 2003;33(1):13-31.

3. Klämpfl $\mathrm{MK}$, Lobinger $\mathrm{BH}$, Raab $\mathrm{M}$. How to detect the yips in golf. Hum Mov Sci 2013;32(6):1270-87.

4. Bawden M, Maynard I. Towards an understanding of the personal experience of the 'yips' in cricketers. J Sports Sci 2001;19(12):937-53.

5. Adler CH. Sports-related task-specific dystonia: The yips. Handbook of Dystonia 2006:209.

6. Mesagno C. Investigating the use of choking intervention strategies with choking-susceptible athletes. Victoria University 2006.

7. Klämpfl $\mathrm{MK}$, Lobinger $\mathrm{BH}$, Raab $\mathrm{M}$. Reinvestment-the Cause of the Yips? PloS one 2013;8(12):e82470.

8. McDaniel KD, Cummings JL, Shain S. The "yips" A focal dystonia of golfers. Neurology 1989;39(2):192.

9. Smith AM, Malo SA, Laskowski ER, et al. A multidisciplinary study of the 'yips' phenomenon in golf. Sports Med 2000;30(6):423-37.

10. Philippen PB, Legler A, Land WM, et al. Diagnosing and measuring the yips in golf putting: A kinematic description of the involuntary movement component that is the yips. Sport Exerc Perform Psychol 2014;3(3):149.

11. Dhungana S, Jankovic J. Yips and other movement disorders in golfers. Mov Disord 2013;28(5):576-81.

12. Stinear CM, Coxon JP, Fleming MK, et al. The yips in golf: Multimodal evidence for two subtypes. Med Sci Sports Exerc 2006;38(11):1980.

13. Altenmüller E, Müller D. A model of task-specific focal dystonia. Neural Netw 2013;48:25-31.

14. Chang FCF, Frucht SJ. Motor and sensory dysfunction in musician's dystonia. Curr Neuropharmacol 2013;11(1): 41-7. 
Citation: Mine K, Ono K, Tanpo N. Effectiveness of management for yips in sports: A systematic review. J Phys Ther Sports Med 2018;2(1): $17-25$.

15. Filipović S, Ljubisavljević M, Svetel M, et al. Impairment of cortical inhibition in writer's cramp as revealed by changes in electromyographic silent period after transcranial magnetic stimulation. Neurosci Lett 1997;222(3):167-70.

16. Elbert T, Candia V, Altenmüller E, et al. Alteration of digital representations in somatosensory cortex in focal hand dystonia. Neuroreport 1998;9(16):3571-5.

17. Castrop F, Dresel C, Hennenlotter A, et al. Basal gangliapremotor dysfunction during movement imagination in writer's cramp. Mov Disord 2012;27(11):1432-9.

18. Hill DM, Hanton S, Matthews N, et al. Choking in sport: A review. Int Rev Sport Exerc Psychol 2010;3(1):24-39.

19. Wang J, Marchant D, Morris T, et al. Self-consciousness and trait anxiety as predictors of choking in sport. J Sci Med Sport 2004;7(2):174-85.

20. Jackson RC, Ashford K, Norsworthy G. Attentional focus, dispositional reinvestment, and skilled motor performance under pressure. J Sport Exerc Psychol 2006;28: 49-68

21. Bell RJ, Thompson CL. Solution-focused guided imagery for a golfer experiencing the yips: a case study. Athl Insight 2007;9(1):52-66.

22. Mesagno C, Marchant D, Morris T. A pre-performance routine to alleviate choking in "choking-susceptible" athletes. The Sport Psychologist 2008;22(4):439-57.

23. Mesagno C, Marchant D, Morris T. Alleviating choking: The sounds of distraction. J Appl Sport Psychol 2009;21(2):131-47.

24. Abbruzzese G, Berardelli A. Sensorimotor integration in movement disorders. Mov Disord 2003;18(3):231-40.

25. Neychev VK, Gross R, Lehéricy S, et al. Golf Putting "Yips": Focal Dystonia Research. Neurobiol Dis 2011;42(2):185-201.

26. Rosted P. Acupuncture for treatment of the yips?-A case report. Acupunct Med 2005;23(4):188-9.

27. Moher D, Liberati A, Tetzlaff J, et al. Preferred reporting items for systematic reviews and meta-analyses: the PRISMA statement. Ann Intern Med 2009;151(4):264-9.

28. Moher D, Liberati A, Tetzlaff J, et al. Preferred reporting items for systematic reviews and meta-analyses: the PRISMA statement. Int J Surg 2010;8(5):336-41.

29. Law M, Stewart D, Pollock N, et al. Critical review formquantitative studies. McMaster University: Occupational Therapy Evidence-Based Practice Research Group. 1998.

30. Hedges LV. Distribution theory for Glass's estimator of effect size and related estimators. J Educ Behav Stat 1981;6(2):107-28.

31. Cohen J. A power primer. Psychol Bull 1992;112(1):155.

32. Beckmann J, Gröpel P, Ehrlenspiel F. Preventing motor skill failure through hemisphere-specific priming: Cases from choking under pressure. Journal of Experimental Psychology: General 2013;142(3):679.

33. Mesagno C, Mullane-Grant T. A comparison of different pre-performance routines as possible choking interventions. J Appl Sport Psychol 2010;22(3):343-60.
34. Oudejans RR, Pijpers JR. Training with mild anxiety may prevent choking under higher levels of anxiety. Psychol Sport Exerc 2010;11(1):44-50.

35. Reeves JL, Tenenbaum G, Lidor R. Choking in front of the Goal: The effects of self-consciousness training. Int Rev Sport Exerc Psychol 2007;5(3):240-54.

36. Schücker L, Ebbing L, Hagemann N. Learning by Analogies: Implications for performance and attentional processes under pressure. Hum Mov 2010;11(2):191-9.

37. Kagawa M. Effects of mental training with self-monitoring and cognitive restructuring by video feedback for a college baseballplayer with yips symptom. Japanese Mental Training Journal 2013;7:35-44.

38. Bell RJ, Skinner CH, Halbrook MK. Solution-focused guided imagery as an intervention for golfers with the yips. Journal of Imagery Research in Sport and Physical Activity 2011;6(1).

39. Leveille LA, Clement DB. Case report: action-induced focal dystonia in long distance runners. Clin J Sport Med 2008;18(5):467-8.

40. Wu LJ, Jankovic J. Runner's dystonia. J Neurol Sci 2006;251(1):73-6.

41. Kobori O. Cognitive behavioural formulation for focal dystonia in a student athlete: A case report. Behav Cogn Psychother 2007;35(02):245-9.

42. Bell RJ, Skinner CH, Fisher LA. Decreasing putting yips in accomplished golfers via solution-focused guided imagery: A single-subject research design. J Appl Sport Psychol 2009;21(1):1-14.

43. Hill DM, Hanton S, Matthews N, et al. Alleviation of choking under pressure in elite golf: An action research study. The Sport Psychologist 2011;25(4):465-88.

44. Milne D, Morrison G. Cognitive behavioural intervention for the golf yips: A single-case design. J Sport Exerc Psychol 2015:20.

45. Rotheram M, Maynard I, Thomas O, et al. Preliminary evidence for the treatment of type I 'yips': The efficacy of the emotional freedom techniques. The Sport Psychologist 2012;26(4):551-70.

46. Idol E. Always look on the bright side of life. Monty Python's Life of Brian: Python (Monty) Pictures Ltd. 1979.

47. Wallwork SB, Bellan V, Catley MJ, et al. Neural representations and the cortical body matrix: implications for sports medicine and future directions. Br J Sports Med 2016;50(16):990-6.

48. Fiorio M, Tinazzi M, Aglioti SM. Selective impairment of hand mental rotation in patients with focal hand dystonia. Brain 2006;129(1):47-54.

49. Reinersmann A, Landwehrt J, Krumova EK, et al. Impaired spatial body representation in complex regional pain syndrome type 1 (CRPS I). PAIN 2012;153(11):2174-81.

50. Moseley GL. Graded motor imagery for pathologic pain A randomized controlled trial. Neurology 2006;67(12): 2129-34. 
*Correspondence to:

Koya Mine

Department of Physical Therapy

School of Health Sciences

Tokyo University of Technology
5-23-22 Nishi-kamata, Ota ward

Tokyo, Japan

Tel: +81364242210

E-mail: mineky@stf.teu.ac.jp 